\title{
Asymmetric Polymerization of 9-Phenylfluoren-9-yl Methacrylate Leading to a Polymer with Main-Chain Configurational Chirality. Synthesis of Optically Active Poly(methyl methacrylate)
}

\author{
Tamaki NaKano, Yasuaki Hidaka, and Yoshio OKamoto \\ Department of Applied Chemistry, Graduate School of Engineering, Nagoya University, \\ Furo-cho, Chikusa-ku, Nagoya 464-8603, Japan
}

(Received January 21, 1998)

\begin{abstract}
Polymerization of 9-phenylfluoren-9-yl methacrylate was carried out aiming at obtaining highly isotactic, single-handed helical polymers using the complexes of $N, N^{\prime}$-diphenylethylenediamine monolithium amide with (-)-sparteine, (+)-1-(2-pyrrolidinylmethyl)pyrrolidine, and (+)-2,3-dimethoxy-1,4-bis(dimethylamino)butane. Although the isotacticity $(m m=55-46 \%)$ and specific rotation $\left([\alpha]_{365}-54+119^{\circ}\right)$ of the obtained polymers were much lower than those of known single-handed helical polymethacrylates, the poly(methyl methacrylate) (PMMA) derived from the obtained polymers exhibited rather high optical activity $\left([\alpha]_{365}-44-11^{\circ}\right)$ for a polymer which does not take any stable, chiral conformation. The optical activity of the PMMA was attributed to configurational chirality of the main chain.

KEY WORDS 9-Phenylfluoren-9-yl Methacrylate / Asymmetric Polymerization / Anionic Polymerization / Conformation / Configuration / Helix / Chiral /
\end{abstract}

Chiral synthetic polymers are of interest due to their potential ability in applications such as molecular recognition, construction of supramolecular assembly system, and liquid crystalline formation. ${ }^{1-5}$ From the view of synthetic organic chemistry, the polymers having chirality induced into their structure through polymerization of achiral or prochiral monomers are more important than the polymers made simply by polymerization of chiral monomers. In this context, two principal types of polymerization which enable chirality induction have been realized, namely, polymerization inducing configurational chirality in the main chain (asymmetric synthesis polymerization) and polymerization inducing single-handed helical conformation of the main chain (helix-sense-selective polymerization). We have already succeeded in realizing the latter type of asymmetric polymerization using bulky methacrylates including triphenylmethyl methacrylate (TrMA) ${ }^{6,7}$ and 1-phenyldibenzosuberyl methacrylate (PDBSMA) ${ }^{8}$ : helical conformation of the polymethacrylates is stabilized by the steric repulsion of the bulky side groups.

In the present study, we carried out asymmetric anionic polymerization of 9-phenylfluoren-9-yl methacrylate (PFMA) having a bulky side group similar to those of TrMA and PDBSMA and investigated the structure and the chiroptical properties of the obtained polymers. Although we originally aimed at helix-sense-selective polymerization of PFMA, no clear evidence of helical polymer formation was indicated. However, interestingly, the obtained poly (PFMA)s appeared to have main-chain
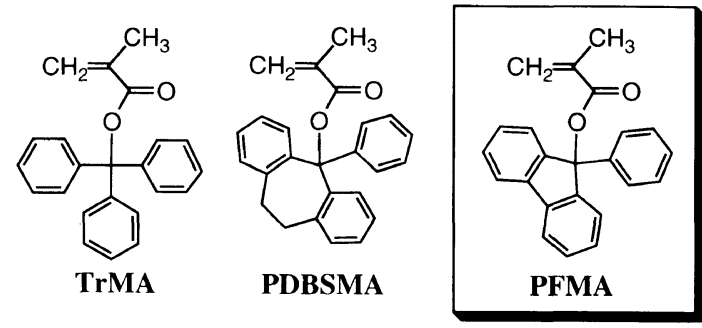

configurational chirality and hence the poly(methyl methacrylate)s (PMMAs) derived from the poly(PFMA)s were optically active. This paper describes the results of the anionic polymerization and discusses the origin of chiroptical properties of the obtained polymers and the PMMAs derived therefrom.

\section{EXPERIMENTAL}

\section{Material}

Fluorenone (Tokyo Chemical Industry) was used as obtained. Diethyl ether and tetrahydrofuran (THF) were distilled over $\mathrm{Na}$ wire and stored under nitrogen in the dark. Purification of the other materials including those for anionic polymerization has been shown in the literature. ${ }^{7}$

\section{Synthesis of PFMA}

9-Phenylfluoren-9-ol was prepared by the reaction of fluorenone with phenylmagnesium bromide in tetrahydrofuran. mp $103.0-104.5^{\circ} \mathrm{C}$ (lit. ${ }^{9} 107^{\circ} \mathrm{C}$ ). The monomer was synthesized in a method different from that reported previously. ${ }^{10}$ In a $2-\mathrm{L}$ flask equipped with a dropping funnel was placed $\mathrm{NaH}$ ( $60 \mathrm{wt} \%$ oil suspension) $(34.83 \mathrm{~g}, 0.871 \mathrm{~mol})$. THF $(100 \mathrm{ml})$ was introduced with a syringe and the mixture was stirred to remove oil from $\mathrm{NaH}$. After stirring was stopped, the supernatant THF wash was removed with a syringe. Fresh THF $(200 \mathrm{ml})$ was added to the washed $\mathrm{NaH}$ and 9-phenylfluoren-9-ol $(150 \mathrm{~g}, 0.581 \mathrm{~mol})$ dissolved in $500 \mathrm{ml}$ of THF was added dropwise in a 1.5 -h period with stirring at room temperature. After completion of $\mathrm{H}_{2}$ generation, methacryloyl chloride $(68.1 \mathrm{ml}, 0.697 \mathrm{~mol})$ dissolved in THF $(300 \mathrm{ml})$ was added dropwise to the mixture which was cooled at $0^{\circ} \mathrm{C}$ in the dark with stirring in a 1-h period. After stirring for additional $1 \mathrm{~h}$ at $0^{\circ} \mathrm{C}$, the reaction mixture was decomposed by carefully adding water $(500 \mathrm{ml})$. The products were extracted using ether and recrystallized first from a mixture of ether and hexane $(1 / 1, v / v)$, then from a mixture of benzene and hexane 
Table I. Asymmetric anionic polymerization with DPEDA-Li complexes in toluene ${ }^{a}$

\begin{tabular}{|c|c|c|c|c|c|c|c|c|c|c|c|}
\hline \multirow{2}{*}{ Run } & \multirow{2}{*}{ Monomer } & \multirow{2}{*}{ Ligand } & \multirow{2}{*}[\mathrm{M}]{$/[\mathrm{I}]$} & \multirow{2}{*}{$\frac{\text { Temp }}{{ }^{\circ} \mathrm{C}}$} & \multirow{2}{*}{$\frac{\text { Yield }^{b}}{\%}$} & \multirow{2}{*}{$\frac{[\alpha]_{365}^{25}}{\operatorname{deg}}$} & \multirow{2}{*}{$\mathrm{DP}^{\mathrm{d}}$} & \multirow{2}{*}{$M_{w} / M_{n}{ }^{\mathrm{d}}$} & \multicolumn{3}{|c|}{ Tacticity $/ \%$} \\
\hline & & & & & & & & & $\mathrm{mm}$ & $m r$ & $r r$ \\
\hline 1 & PFMA & (+)-PMP & 20 & 0 & 86 & +16 & 42 & 1.21 & 58 & 30 & 12 \\
\hline 2 & PFMA & (+)-PMP & 20 & -40 & 94 & n.d. ${ }^{f}$ & 40 & 1.19 & 68 & 21 & 11 \\
\hline 3 & PFMA & (+)-PMP & 20 & -78 & 95 & +30 & 41 & 1.20 & 54 & 25 & 21 \\
\hline 4 & PFMA & (+)-PMP & 40 & -78 & 96 & +107 & 80 & 1.20 & 55 & 24 & 21 \\
\hline 5 & PFMA & (+)-PMP & 60 & -78 & $>99$ & +119 & 99 & 1.22 & 54 & 24 & 22 \\
\hline 6 & PFMA & (+)-PMP & 70 & -78 & $>99$ & n.d. ${ }^{f}$ & 116 & 1.28 & 54 & 24 & 22 \\
\hline 7 & PFMA & (+)-PMP & 100 & -78 & 78 & n.d. ${ }^{f}$ & 122 & 1.46 & 51 & 25 & 24 \\
\hline 8 & PFMA & $(+)$-PMP & 150 & -78 & 52 & n.d. ${ }^{f}$ & 135 & 1.22 & 49 & 28 & 23 \\
\hline 9 & PFMA & (+)-PMP & 200 & -78 & 53 & n.d. ${ }^{\mathrm{f}}$ & 151 & 1.22 & 47 & 28 & 25 \\
\hline 10 & PFMA & (+)-PMP & 20 & -95 & $>99$ & -54 & 41 & 1.15 & 46 & 22 & 32 \\
\hline 11 & PFMA & $(+)-\mathrm{DDB}$ & 20 & -78 & 96 & -16 & 39 & 1.17 & 46 & 32 & 22 \\
\hline 12 & PFMA & $(-)-S p$ & 20 & -78 & 50 & -2 & 29 & 1.18 & 48 & 35 & 17 \\
\hline $13^{\mathrm{g}}$ & TrMA & $(+)$-PMP & 20 & -78 & $>99$ & $+1350^{\mathrm{i}}$ & $39^{i}$ & $1.12^{\mathrm{i}}$ & $>99^{i}$ & $<1^{\mathrm{i}}$ & $<1^{\mathrm{i}}$ \\
\hline $14^{\mathrm{h}}$ & PDBSMA & (+)-PMP & 20 & -78 & $>99$ & $+1780^{\mathrm{i}}$ & $43^{i}$ & $1.10^{\mathrm{i}}$ & $>99^{\mathrm{i}}$ & $<1^{\mathrm{i}}$ & $<\mathrm{l}^{\mathrm{i}}$ \\
\hline
\end{tabular}

${ }^{\mathrm{a}}$ Conditions: monomer $1.0 \mathrm{~g}$, toluene $20 \mathrm{ml}$, time $48 \mathrm{~h} .{ }^{\mathrm{b}} \mathrm{MeOH}$-insoluble part. ${ }^{\mathrm{c}}$ Measured in THF. ${ }^{\mathrm{d}}$ Determined by GPC analysis of the PMMA derived from the original polymer. ${ }^{\mathrm{c}}$ Determined by $500 \mathrm{MHz}{ }^{1} \mathrm{H}$ NMR analysis of the PMMA derived from original polymer. ${ }^{\mathrm{f}}$ Not determined because the polymer was not completely soluble in THF. ${ }^{\mathrm{g}}$ The same reaction has been reported (ref 7). ${ }^{\mathrm{h}}$ The same reaction has been reported (ref 8$)$. ' P Properties of benzene-hexane (1/1)-insoluble part of the products.

$(1 / 1, \mathrm{v} / \mathrm{v})$, and finally from pure hexane to yield pure colorless crystals of PFMA. Yield $77.0 \mathrm{~g}(41.0 \%)$. mp $132.5-133.5^{\circ} \mathrm{C}\left(\right.$ lit. $\left.^{10} 150-151^{\circ} \mathrm{C}\right) .{ }^{1} \mathrm{H}$ NMR $(400 \mathrm{MHz}$, $\left.\mathrm{CDCl}_{3}, \mathrm{Me}_{4} \mathrm{Si}\right) \delta 7.72(\mathrm{~d}, 2 \mathrm{H}$, aromatic $\mathrm{H}), 7.38(\mathrm{~d}, 2 \mathrm{H}$, aromatic $\mathrm{H}), 7.21-7.33(\mathrm{~m}, 9 \mathrm{H}$, aromatic $\mathrm{H}), 6.22(\mathrm{~m}$, $1 \mathrm{H}$, vinyl $\mathrm{H}), 5.60(\mathrm{~m}, 1 \mathrm{H}$, vinyl $\mathrm{H}), 1.94\left(\mathrm{~s}, 3 \mathrm{H}, \alpha-\mathrm{CH}_{3}\right)$. IR (KBr) $1636 \mathrm{~cm}^{-1}(\mathrm{C}=\mathrm{C}), 1731 \mathrm{~cm}^{-1}(\mathrm{C}=\mathrm{O})$. Anal. Calcd for $\mathrm{C}_{24} \mathrm{H}_{21} \mathrm{O}_{2} \mathrm{~N}$ : C, $84.64 \% ; \mathrm{H}, 5.56 \%$. Found: C, $84.11 \% ; \mathrm{H}, 5.57 \%$. FD Mass $m / z=326.0($ calcd 326.1$)$.

Methanolysis rate constant of PFMA was determined to be $k=0.19 \mathrm{~h}^{-1}$ (half-life period $224 \mathrm{~min}$ ) by methanolysis experiment in $\mathrm{CD}_{3} \mathrm{OD}-\mathrm{CDCl}_{3}(1: 1)$ at $35^{\circ} \mathrm{C}$.

\section{Polymerization}

The method of polymerization is the same as that reported for TrMA ${ }^{7}$ except that $N, N^{\prime}$-diphenylethylenediamine monolithium amide (DPEDA-Li) was used as an initiator instead of 9-fluorenyllithium. See Table I for more details of the reaction conditions. Part of the obtained polymer was converted to methyl ester (PMMA) by solvolysis of the ester group using $\mathrm{MeOH}$ containing $\mathrm{HCl}$ followed by methylation using $\mathrm{CH}_{2} \mathrm{~N}_{2}$. Conversion of poly(PFMA) to PMMA was confirmed by ${ }^{1} \mathrm{H}$ NMR analysis. Tacticity of the polymers was determined by ${ }^{1} \mathrm{H}$ NMR analysis $\left(\mathrm{CDCl}_{3}, 60^{\circ} \mathrm{C}\right)$ of PMMA derived from the original polymer. The degree of polymerization (DP) and molecular weight distribution of the polymers were determined by GPC of the PMMA using a polystyrene calibration curve.

\section{Measurement}

${ }^{1} \mathrm{H}$ NMR spectra were taken on a Varian Gemini 2000 spectrometer ( $400 \mathrm{MHz}$ for ${ }^{1} \mathrm{H}$ measurement). IR spectra were taken on a JASCO FT/IR-7000 spectrometer. Optical rotation was measured with a JASCO DIP-181 polarimeter using a $0.5-\mathrm{dm}$ quartz cell. GPC was performed with a Shodex System-21 GPC system equipped with a Shodex RI-71S detector and JASCO OR990 polarimetric detector using Shodex KF-803 and KF806F GPC columns connected in series (eluent, THF; flow rate, $1.0 \mathrm{ml} \mathrm{min}^{-1}$; temp, $40^{\circ} \mathrm{C}$ ).

\section{RESULTS AND DISCUSSION}

\section{Attempted Helix-Sense-Selective Polymerization of PFMA}

Helix-Sense-Selective polymerization of PFMA has been attempted by a different group and the polymerization in toluene using (-)-sparteine ( $\mathrm{Sp}$ )-BuLi complex was reported to give only oligomers $(\mathrm{DP}=4-14) .{ }^{10} \mathrm{In}$ the present study, anionic polymerization of PFMA was carried out in toluene using the complexes of DPEDA-Li with Sp, (+)-1-(2-pyrrolidinylmethyl)pyrrolidine (PMP), and (+)-2,3-dimethoxy-1,4-bis(dimethylamino)butane (DDB). The conditions and results of polymerization are shown in Table I along with those of TrMA and PDBSMA polymerization for comparison.<smiles>Oc1ccccc1NCCNc1ccccc1</smiles><smiles>C1=CN=CC2(C1)CCCN2</smiles>

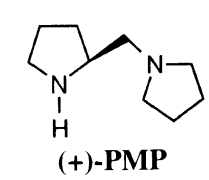<smiles>COC(CN(C)C)C(OC)OC</smiles>

(+)-DDB
The reaction gave polymers with higher DPs compared with those in the previous report. ${ }^{10}$ In addition, most of the obtained polymers had narrow molecular weight distribution and DP of the polymer increased with increasing [monomer]/[initiator] ratio in the polymerization using PMP-DPEDA-Li at $-78^{\circ} \mathrm{C}$, suggesting a possibility of living polymerization. However, the poly(PFMA)s exhibited much lower isotacticity and smaller optical activity (runs 1-12) compared with the poly(TrMA) and the poly(PDBSMA) (runs 13 and 14) having single-handed helical conformation synthesized using (+)-PMP-initiator system. As for the polymerization of PFMA with PMP-DPEDA-Li complex, iso- 
Table II. Asymmetric anionic copolymerization of PFMA with PDBSMA using DPEDA-Li- $(+)-\mathrm{PMP}$ complex in toluene at $-78^{\circ} \mathrm{C}^{\mathrm{a}}$

\begin{tabular}{|c|c|c|c|c|c|c|c|c|}
\hline \multirow{2}{*}{ Run } & \multirow{2}{*}{$\frac{[\text { PDBSMA }]_{0}}{\left[\begin{array}{c}\text { PFMA }]_{0}+[\text { PDBSMA }]_{0} \\
\text { in feed }\end{array}\right.}$} & \multirow{2}{*}{$\frac{\text { Conversion }^{\mathrm{b}}}{\%}$} & \multirow{2}{*}{$\frac{[\alpha]_{365}^{25} \mathrm{c}}{\operatorname{deg}}$} & \multirow{2}{*}{$\mathrm{DP}^{\mathrm{d}}$} & \multirow{2}{*}{$M_{w} / M_{n}^{\mathrm{d}}$} & \multicolumn{3}{|c|}{ Tacticity $/ \%^{\mathrm{e}}$} \\
\hline & & & & & & $m m$ & $m r$ & $r r$ \\
\hline $1^{f}$ & 0 & $>99$ & +30 & 41 & 1.20 & 54 & 25 & 21 \\
\hline 2 & 0.2 & $>99$ & +85 & 43 & 1.18 & 69 & 17 & 14 \\
\hline 3 & 0.4 & $>99$ & +337 & 45 & 1.21 & 79 & 12 & 9 \\
\hline 4 & 0.6 & $>99$ & +663 & 48 & 1.20 & 89 & 7 & 4 \\
\hline 5 & 0.8 & $>99$ & +1037 & 50 & 1.14 & 95 & 3 & 2 \\
\hline $6^{g}$ & 1.0 & $>99$ & +1780 & 43 & 1.10 & $>99$ & $<1$ & $<1$ \\
\hline
\end{tabular}

${ }^{a}$ Conditions: monomer $1.0 \mathrm{~g}$, toluene $20 \mathrm{ml}$, [monomer] $/[\mathrm{Li}]=20$, time $48 \mathrm{~h}$. ${ }^{\mathrm{b}}$ Determined by ${ }^{1} \mathrm{H} \mathrm{NMR}$ analysis of the crude products. ${ }^{\mathrm{c}}$ Measured in THF. ${ }^{\mathrm{d}}$ Determined by GPC analysis of the PMMA derived from the original copolymer. ${ }^{\mathrm{e}}$ Determined by $500 \mathrm{MHz}$ ${ }^{1} \mathrm{H}$ NMR analysis of PMMA derived from the original copolymer. ${ }^{\mathrm{f}}$ Run 3 in Table I. ${ }^{8}$ Run 14 in Table I.

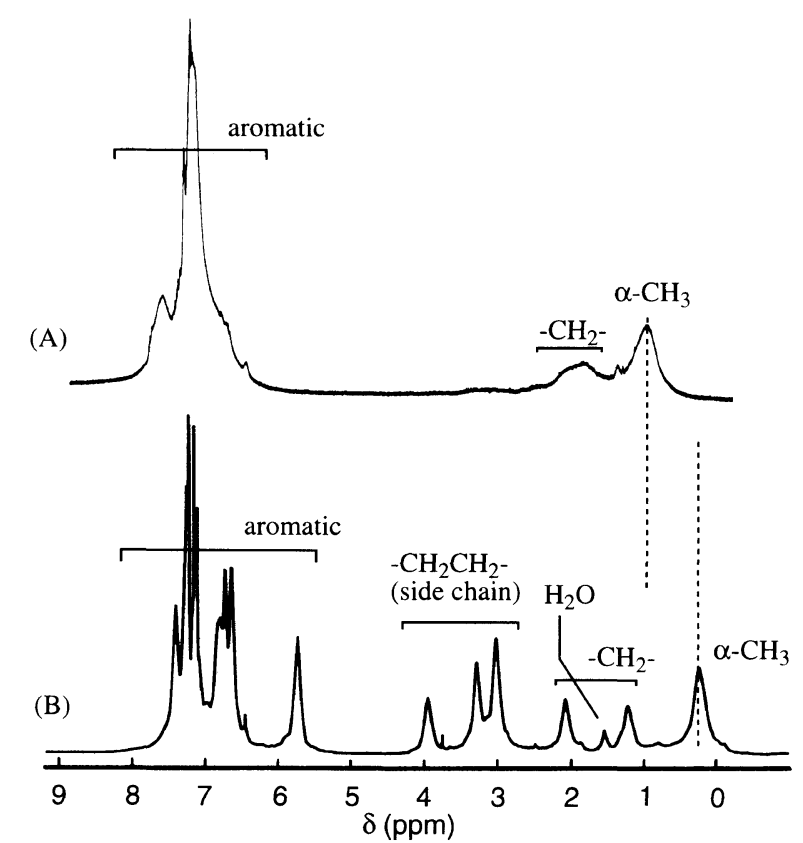

Figure 1. ${ }^{1} \mathrm{H}$ NMR spectra of poly(PFMA) (run 3 in Table I) (A) and poly(PDBSMA) (run 14 in Table I) (B). [400 $\mathrm{MHz} \mathrm{CDCl}_{3}, 60^{\circ} \mathrm{C}$ ]

tacticity and optical activity of the polymer were affected by polymerization temperature as well as [monomer]/ [initiator $]([\mathrm{M}] /[\mathrm{I}])$ ratio of polymerization (runs $1-10$ ) but the highest tacticity and specific rotation observed were only $\mathrm{mm} 68 \%$ and $[\alpha]_{365}+119^{\circ}$, respectively. These results suggest that the poly(PFMA)s obtained in the present study may not have a single-handed helical conformation such as that of the poly(TrMA) ${ }^{6,7}$ and the poly(PDBSMA). ${ }^{8}$ This was supported by ${ }^{1} \mathrm{H}$ NMR analysis of poly(PFMA) (Figure 1). The spectrum of the poly(PFMA) indicated the $\alpha-\mathrm{CH}_{3}$ signal in the range $0.7-1.2 \mathrm{ppm}$ similarly to a conformationally flexible PMMA while the single-handed helical poly(PDBSMA) showed its $\alpha-\mathrm{CH}_{3}$ signal in the range $0-0.5 \mathrm{ppm}$ which is characteristic of helical polymethacrylates ${ }^{1,12}$ although the rather broad peak shape which may be based on a rigid conformation of the main chain was common to both spectra. These observations suggest that the poly(PFMA) may take some rigid conformation but it is different from the helical conformation of the poly(PDBSMA).

9-Phenylfluorenyl group may not be a proper structure

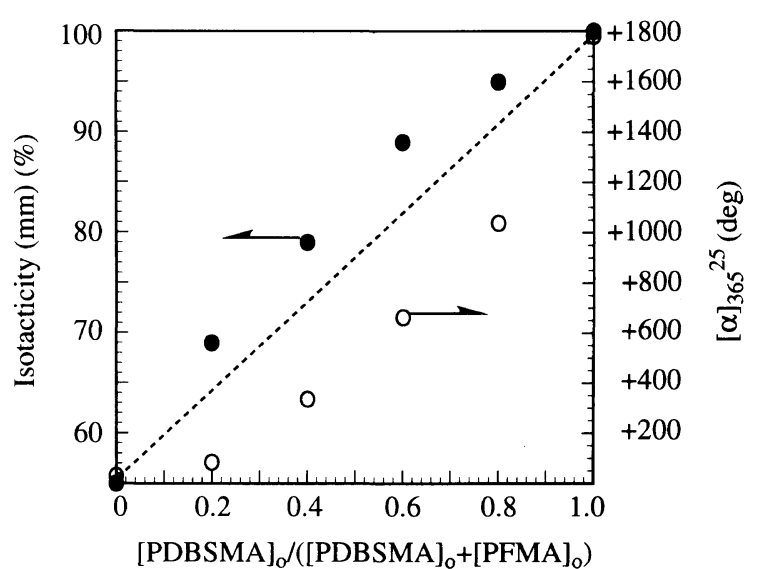

Figure 2. Relations between triad isotacticity (filled circle) and optical activity (open circle) of the copolymers and feed monomer ratio.

to induce and maintain helical conformation of the main chain probably because of the almost planer shape of fluorenyl group: a bulky triaryl group such as a trityl group with the three aryl groups being in propeller shape may be important as a helix-inducing side group.

\section{Asymmetric Anionic Copolymerization of PFMA with PDBSMA \\ Copolymerization of PFMA with PDBSMA was} carried out using PMP-DPEDA-Li as an initiator in toluene at $-78^{\circ} \mathrm{C}$ (Table II, Figure 2) in order to see if the copolymerization can improve helix formation tendency of PFMA units. All reactions at different feed monomer ratios gave polymers with narrow molecular weight distributions with similar DPs. Although both triad isotacticity and specific rotation at $365 \mathrm{~nm}$ of the products increased as the feed ratio of PDBSMA increased, as shown in Figure 2 the observed values did not correspond with the values which were expected based on $[\text { PDBSMA }]_{0} /\left([\text { PFMA }]_{0}+[\text { PDBSMA }]_{0}\right)($ dotted line in the graphs in Figure 2), which rules out the possibility of formation of a block-like copolymer or homopolymers of PFMA and PDBSMA.

Isotacticity of the obtained copolymers was always higher than the values expected based on [PDBSMA] $/$ $\left([\mathrm{PFMA}]_{0}+[\mathrm{PDBSMA}]_{0}\right)$, indicating that isotactic specificity in PFMA addition to the PDBSMA-ended growing anion or that in PDBSMA addition to the PFMA-ended growing anion is higher than the average 
Table III. Optical activity of PMMA derived from poly(PFMA)

\begin{tabular}{|c|c|c|c|c|}
\hline \multirow{2}{*}{ No. } & \multirow{2}{*}{$\begin{array}{l}\text { Original } \\
\text { poly(PFMA)'s } \\
\text { run number in } \\
\text { Table I (chiral } \\
\text { ligand used for } \\
\text { polymerization) }\end{array}$} & $\begin{array}{c}\text { Sample } \\
\text { concentration }\end{array}$ & \multirow{2}{*}{$\frac{\alpha_{365}^{25 a^{a}}}{\operatorname{deg}}$} & \multirow{2}{*}{$\frac{[\alpha]_{365}^{25 a^{a}}}{\operatorname{deg}}$} \\
\hline & & $\mathrm{g} \mathrm{dl}^{-1}$ & & \\
\hline 1 & Run 3 (PMP) & 0.407 & -0.090 & $-44 \pm 1^{b}$ \\
\hline 2 & Run 4 (PMP) & 0.567 & -0.047 & $-17 \pm 1^{b}$ \\
\hline 3 & Run 5 (PMP) & 0.754 & -0.084 & $-22 \pm 1^{b}$ \\
\hline 4 & Run 6 (PMP) & 0.733 & -0.047 & $-13 \pm 1^{b}$ \\
\hline 5 & Run 7 (PMP) & & & $-12^{\mathrm{c}}$ \\
\hline 6 & Run 8 (PMP) & 0.323 & -0.018 & $-11 \pm 1^{\mathrm{b}}$ \\
\hline 7 & Run 9 (PMP) & 0.146 & -0.011 & $-15 \pm 3^{b}$ \\
\hline 8 & Run 11 (DDB) & 0.363 & -0.004 & $-2 \pm 1^{b}$ \\
\hline 9 & Run 12 (Sp) & 0.300 & +0.060 & $+38 \pm 1^{\mathrm{b}}$ \\
\hline
\end{tabular}

${ }^{\mathrm{a}}$ Measured in THF using a 5-cm sample cell. ${ }^{\mathrm{b}}$ Based on the limit of error of the polarimeter at $365 \mathrm{~nm}( \pm 0.002)$. ${ }^{c}$ Determined by GPC analysis using a polarimetric detector.

for the homopolymerizations of PDBSMA and PFMA. This may mean that helix forming propensity of PFMA units was improved by copolymerization. However, on the other hand, specific rotation of the copolymers was always lower than the expected values. Helical structure consisting of PFMA and PDBSMA units might show inherently smaller specific rotation compared with the other helical polymethacrylates having comparable excess single-handed helicity.

\section{Main-Chain Configurational Chirality of Poly (PFMA)}

Although effective helix-sense-selective polymerization of PFMA was not achieved either by homopolymerization or by copolymerization as described so far, we found an intriguing fact that PMMAs derived from the poly(PFMA)s synthesized by the chiral initiators showed significant optical activity (Table III). Generally, stereoregular polymers having flexible, random conformation such as isotactic PMMA and polystyrene do not show significant optical activity even if they are synthesized in enantioselective form using optically active polymerization catalysts, i.e., asymmetric centers in the main chain are produced with high stereoselectivity (pseudochiral). This is because the resultant polymers have a plane of symmetry in the main-chain. For example, the isotactic PMMA with $\mathrm{DP}=39$ derived from the optically active poly(TrMA) (run 13 in Table I) having - SSS -mainchain absolute configuration shows $[\alpha]_{365}^{25}$ of only $+3^{\circ}$ which is much smaller than the rotation of the PMMAs with a similar DP derived from poly(PFMA)s synthesized with PMP- and Sp-initiator systems. The small optical activity is considered to be based on the effect of chiral centers in the vicinity of chain terminals whose contribution increases as the DP decreases. We previously estimated specific rotation $\left([\alpha]_{365}\right)$ of antipodes of optically pure pentamer $(\mathrm{mmmm})$ and octamer (mmmmmmr) to be $26^{\circ}$ and $23^{\circ}$, respectively, by HPLC resolution experiments. ${ }^{13}$ Although the contribution of asymmetric centers at the chain terminals to optical activity should be much larger for the oligomers than for the polymers, the specific rotation values of the PMMAs of No. $1(\mathrm{DP}=41)$ and No. $9(\mathrm{DP}=29)$ in Table III are much larger than the values of the oligomers.

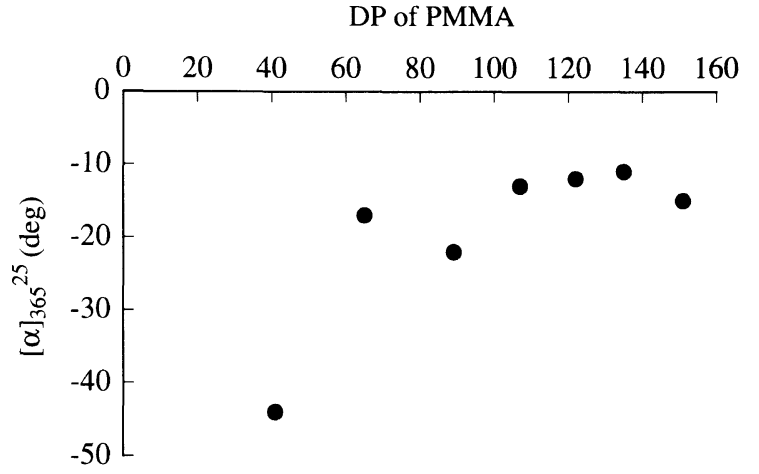

Figure 3. Dependence of optical activity of PMMA derived from poly(PFMA) prepared with PMP-DPEDA-Li at various $[\mathrm{M}] /[\mathrm{I}]$ ratios on degree of polymerization.

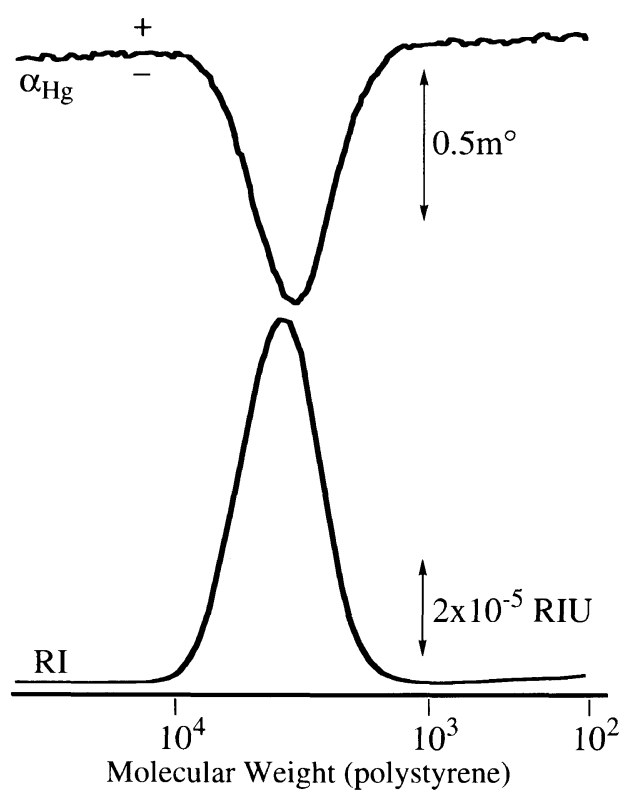

Figure 4. GPC chromatograms of PMMA (No. 1 in Table III) obtained using polarimetric (top) and RI (bottom) detectors.

These results strongly suggest that the optical activity of the PMMAs is at least in part based on in-chain chiral centers.

In order to further clarify the contribution of the chain-end effects on the observed optical activity of the PMMA derived from the poly(PFMA), specific rotation of the PMMAs was plotted against the DP (Figure 3). Optical activity of the PMMA had a tendency to decrease with increasing DP and appeared to become constant $\left([\alpha]_{365}^{25}-11--15^{\circ}\right)$ in the DP range of $c a .120-150$. The specific rotation, $[\alpha]_{365}^{25}-15^{\circ}$ of the polymers with $\mathrm{DP}=151$ was still much higher than the value for the isotactic PMMA with $\mathrm{DP}=39$ having - SSS - absolute configuration $\left(+3^{\circ}\right)$. These results indicate that the optical activity of the PMMAs derived from the PFMAs is not based only on the chain-terminal chiral centers but also on the in-chain chiral centers. As a conclusion, it can be said that the polymers obtained by asymmetric polymerization of PFMA have configurational chirality of main chain. There are examples of optically active PMMA $^{14}$ and polystyrene ${ }^{15}$ prepared though cyclopolymerization of bifunctional monomers. The PMMA had a specific rotation, $[\alpha]_{405}^{20}-4.3^{\circ}$. However, as far as 
(A)

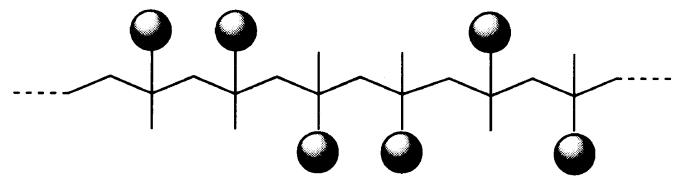

(B)

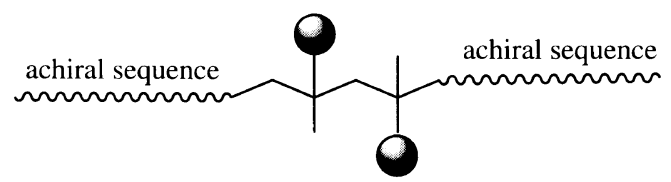

Figure 5. Chiral $m r m r r$ hexad (A) and chiral $r$ dyad isolated in achiral sequences (B).

polymerization of a monofunctional monomer is concerned, the present work is considered to be the first example of synthesis of configurationally chiral vinyl polymer.

GPC analysis of the levorotatory PMMA of No. 1 in Table III using RI and polarimetric detectors gave additional information on the chiral structure of the polymer (Figure 4). The discrepancy in the peak top positions of the two chromatograms with that of the polarimetric chromatogram being slightly shifted toward the lower-molecular-weight end indicates that lowermolecular-weight fractions have higher optical activity, which is consistent with the results shown in Figure 3. However, the peak shapes of the two chromatograms were very similar and no dextrorotatory fractions were detected. This suggests that the original poly(PFMA) may be produced by a single active species in the polymerization, i.e., all chains of the polymer and the PMMA derived therefrom may have statistically similar chiral configuration.

Configurationally chiral, optically active vinyl homopolymers can be realized by synthesizing a virtually chiral stereosequence having no mirror planes or by synthesizing a shorter chiral sequence isolated in achiral sequences in enantiomerically enriched form (Figure 5). ${ }^{1,3,4}$ The shortest stereosequence which meets the criteria of the former and the latter cases are $m r m r r$ hexad and $r$ dyad, respectively. Although what stereosequence is responsible for the optical activity of the PMMAs obtained in the present study is not immediately known, a relatively shorter, isolated chiral sequence rather than the chiral hexad may be more likely because ${ }^{13} \mathrm{C}$ NMR analysis of the PMMA of No. 1 in Table III did not show clear preference of $m r m r r$ hexad sequence $(\mathrm{mmmm} / \mathrm{mmmr}$ ) $r m m r / m m r m+r m r m / m m r r+r m r r / m r r m / m r r r / r r r r=37$ $13 / 3 / 9 / 17 / 6 / 6 / 9)$. The stereostructure of this PMMA was found not to obey a Bernoulli model nor a firstorder Markov model. ${ }^{16}$ This suggests that the stereoregulation (chiral induction) in the monomer addition may not simply depend on the configuration of penultimate and penpenultimate monomeric units (the second and the third units from the active end) but may rather be influenced by the stereostructure of longer monomeric sequences as well as the chirality of the ligand used for polymerization.

\section{CONCLUSION}

Asymmetric polymerization of PFMA with chiral anionic initiators gave polymers with main-chain configurational chirality though the initial objective of the research to obtain single-handed helical polymers was not achieved. Efforts are under way to learn precise configurational structure which causes the optical activity of the PMMAs and the extent of chiral induction.

\section{REFERENCES}

1. Y. Okamoto and T. Nakano, Chem. Rev., 94, 349 (1994).

2. T. Nakano and Y. Okamoto, in "The Polymeric Materials Encyclopedia," J. C. Salamone, Ed., CRC Press, Florida, 1996, pp $417-423$.

3. M. Farina, Top. Stereochem., 17, 1 (1987).

4. G. Wulff, Angew. Chem., Int. Ed. Engl., 28, 21 (1989).

5. G. Wulff, CHEMTECH, 364 (1991).

6. Y. Okamoto, K. Suzuki, K. Ohta, K. Hatada, and H. Yuki, J. Am. Chem. Soc., 101, 4763 (1979).

7. T. Nakano, Y. Okamoto, and K Hatada, J. Am. Chem. Soc., 114, $1318(1992)$

8. T. Nakano, A. Matsuda, M. Mori, and Y. Okamoto, Polym. J., 28, 330 (1996).

9. F. Ulmann and R. Wurstemberger, Ber., 64, 73 (1904).

10. T. Oishi, M. Fujimoto, T. Hirota, and S. Kajigaeshi, J. Macromol, Sci.-Chem., A23, 687 (1986).

11. T. Nakano, Y. Satoh, and Y. Okamoto, Polym. J., in press.

12. Y. Okamoto, K. Suzuki, and H. Yuki, J. Polym. Sci., Polym. Chem. Ed., 19, 3043 (1981).

13. Y. Okamoto, T. Nakano, and K. Hatada, Polym. J., 21, 199 (1989).

14. T. Kakuchi, H. Kawai, S. Katoh, O. Haba, and K. Yokota, Macromolecules, 25, 5545 (1992).

15. G. Wulff and P. K. Dhal, Angew. Chem., Int. Ed. Engl., 28, 196 (1989).

16. G. Moad, D. H. Solomon, T. H. Spurling, S. R. Johns, and R. I. Willing, Aust. J. Chem., 39, 43 (1986). 